\title{
Mode of Operation of Medical Logistics in China
}

\author{
Haihe Guo \\ School of nursing, Jiangxi University of Technology
}

\begin{abstract}
Keywords: Medical logistics; Electronic commerce; Information technology; The third-party logistics
\end{abstract}

\begin{abstract}
This paper adopts the method of theory combining with practice. It firstly expounds the basic concepts and characteristics of medicine logistics, the third-party medical logistics, medicine e-commerce logistics and medicine supply chain management, and it mainly analyzes the current status and existing problems of the medical logistics and circulation of China. Then according to the actual situation of China and the support of new medical reform and other national policies, the paper also analyzes the development strategy and the way of development, such as how to improve the development of medical logistics, how to better develop medicine logistics according to the advantages of the medicine circulation enterprises themselves, how to improve logistics efficiency and reduce logistics costs. The number of the medicine logistics circulation enterprises in China is large but their scales are small. To make a better development of medicine circulation enterprises, strong logistics distribution system, advanced logistics management system and technology, complete supply system with complete supply chain are all needed.Medicine, the noun which is closely linked with our life, is gradually getting into every individual. The medicine logistics also turn in the new era. But there are still problems in medicine logistics. The traditional logistics pattern of China already cannot adapt to the increasingly fierce market competition. The traditional logistics pattern needs to be changed and the logistics pattern needs unceasing reform and continuous exploration.With China's aging population increasing, people's living standards are unceasingly enhancing, medicine and electricity are slowly rising and the concept of online shopping is also gradually accepted by the public. The continuous conversion of shopping concept also provides foundation for medicine e-commerce. The rapid development of medicine e-commerce also injects more vigor into the medical logistics of China.In recent years, China attaches great importance to the reform of urban and rural basic medical system and invests a lot of money to improve the system, which provides large medicine enterprises with unprecedented development opportunities. However, development and competition coexist. Since China's accession to WTO, a large number of foreign enterprises enter China's market. Facing with the strong opponents with strong capital strength, advanced marketing strategy and logistics management advantages, the medicine enterprises in China are facing severe challenges. The disadvantages of the medicine logistics enterprises of China constantly emerge in the escalating competition, such as the backward logistics technology and the uncompleted logistics networks, which then influences the development of the medicine logistics industry in China.
\end{abstract}

\section{The current status analysis of the medicine logistics in China}

Due to the particularity of medicine logistics, the medical logistics in China adopts unified management for a long time. The medicine logistics is basically state-owned. The logistics links are too much and the logistics costs are too high. All the above cause the artificial high price of medicine. The root of the difficulty in medicine treatment is that the price of medicine is too high for the purchasing power of people. In medicine sales, three level distributions are basically the most common distribution sales model. What is three level distribution? Manufacturers produce medicine and wholesale the medicine to wholesale enterprises, then wholesale enterprises again 
conduct distribution and sell the medicine to retail enterprises, such as pharmacy or other retail enterprises. Excessive logistics links will spend a long time for the med icine from the factory to customers. Transportation process is long and the price also increase. Due to the situation of the medicine logistics enterprises of China which is large in number and small in scale, there are many medicine logistics enterprises which do not have large networks to support. What's more, most medicine enterprises are located in Beijing, Shanghai and other first level cities. The distribution is less in three level cities and rural areas. The above situation cause s the medicine logistics be artificially hot in first level cities while the network coverage is not complete in other places.

\section{Discussion on the medicine logistics operation mode of China}

The private logistics development mode. In China, medicine logistics enterprises usually have their own internal logistics system, providing the basic distribution and warehousing services. Due to the small size and single business, the logistics system generally has low operating efficiency and high costs, which is difficult to adapt to the fierce market competition. However, if these dispersed logistics systems are integrated, they can take the advantages of scale economies to reduce enterprise logistics costs.

\section{Medicine logistics mode in e-commerce environment}

Medicine logistics operation mode in e-commerce environment. With the rapid development of information technology and the constant improvement of the related peripheral environment, the electronic commerce with merchandise online marketing as the core develops rapidly. In the face of the tantalizing prospect of e-commerce, many enterprises have focused in this field. In this context, the medicine logistics enterprises of China also actively explore online trading to meet the needs in "E-commerce" era of medicine enterprises.

Compared to those traditional logistics operation modes, the operation mode under the e-commerce environment has no substantial differences. However, e-commerce built a new path for medicine logistics. Through online special electric business platform, dealers can put their own commodity information on the Internet, which virtually attracts a large number of customers, without the need of contacting business at each sale terminal for salesmen, which saves a lot of time and money and avoids some under table dealings.

Prospects of medicine logistics operation model under e-commerce environment. Traditional medicine is relatively easy to implement e-commerce. With the development of network and electricity, the traditional medicine enterprises in China is faced with broad prospects for development. Firstly, due to the characteristics of easy preservation, easy transportation, brands, easy trading, etc. it is easy for the traditional medicine enterprises to implement electronic commerce. Secondly, through the electronic commerce trade, the traditional medicine enterprises cannot only break through the limitation of space and time, but also can greatly reduce costs and make the traditional Chinese medicine to go to the world.

Logistics has always been a bottleneck to the further development of the electronic commerce in our country, which at present is mainly shown as there is no effective social logistics distribution system which can provide products with low-cost, timely, right amount transfer service after the Internet business. The logistics costs is high and the logistics speed is low, which will make customers be dissatisfied who do not always contract online shopping, which greatly hinders the vigorous development of e-commerce and becomes the "bottleneck" for the further development of e-commerce.

The third-party medicine logistics mode. The third-party logistics is a professional logistics service provider. Through professional services, scale economy, low transportation costs and other logistics value-added services, it can bring tangible benefits to customers and it draw more 
enterprises' attention. Being different from the general goods storage and distribution, medicine logistics center is divided into normal temperature warehouse, cool warehouse, frozen warehouse, acceptance curing warehouse, as well as standard colorimetric instrument for quality problems tests. Therefore, the whole process must be in strict accordance with the measures on these links, which can guarantee the quality of medicine products.

\section{Policy suggestions to promote the development of the medicine logistics in China}

Actively promote traditional medicine enterprises to turn to the one with networking and institutionalization. Under the double impact of electronic commerce and supply chain management, the traditional medicine wholesale enterprises are faced with transformation problems. Government is needed to actively guide the large medicine enterprises to conduct annexation and reorganization, to strengthen the construction of its own network and informationization level and to continuously promote the development of modern medicine logistics.

Speed up the construction of medicine logistics informationization and standardization. To speed up the pace of medical logistics informationization construction. The government should conduct special policy and funds for large medicine logistics enterprises, accelerate the construction of the information network in medical logistics market, build medical e-commerce platform, establish supply chain model of medicine industry as soon as possible, improve the supply chain upstream and downstream communication and make it more clear for logistics, information flow and cash flow.

To promote standardization of medicine logistics construction. For China's medicine logistics industry, the medicine coding system is incomplete without unified coding system and relativity, which causes low information of medicine. As a result, the related departments should formulate and carry out a unified system of medicine code as soon as possible.

Use high-tech means of information technology to elaborately control inventory. For logistics enterprises, large inventories will no doubt increase the operating costs, which is not conducive to the control of the logistics costs. Medicine logistics enterprises can use some advanced technology and equipment to control the inventory in order to achieve a best state to make the warehouse be more than a place for storage.

Wide application of RFID technology. In medicine industry, RFID technology has a broad application space. It can improve the efficiency of outbound, avoiding that each product packaging should be scanned which is a waste of time. RFID can ensure that the logistics center buy and receive the correct amount of equipment and medicine. It can improve the inventory turnover ratio and reduce inventory and the final purpose is to reduce costs eventually.

Moreover, RFID tags can make medicine recall have target and operate efficiently, which can save both manpower and material resources. In the United States, it is estimated that in a medicine recall, RFID saved \$16 million management costs and \$10 million to \$20 million brand loss for a medicine enterprise.

Establish logistics distribution center. There are a lot of modern medicine commercial enterprises which have very good conditions to build modern logistics. The key is to, in accordance with the conditions of the modern logistics, integrate the existing resources and gradually make them play each role, put in place step by step and gradually occupy the market. To establish logistics distribution center, the first thing is to give priority to self distribution in facing with hospital, retail pharmacies and other business. The second thing is to attract the major suppliers and establish network partnership with them, to make logistics center become distribution centers or transit warehouses for other products and to expand the functions of logistics centers. The third thing is to enlarge business scale to the storage and distribution of the related products needed by hospitals and pharmacies rather then only the distribution of medicine. 


\section{Conclusions}

Medicine is closely related with people's life. To reduce logistics links and costs in order to reduce the price of medicine has already become the common goal which the medicine logistics enterprises are in pursuit.

And because of the particularity of medicine, the medicine logistics industry in China is still restricted by the state's policy. The medicine logistics industry will develop by using advanced management ideas and technology, researching and developing advanced logistics system, using unified standardization and institutionalization of bar code technology and strengthening the infrastructure construction of medical logistics. In all industries, talents are needed, so it will be helpful for the development of medicine logistics industry to strengthen the publicity power and talents cultivation of the modern logistics.

Along with China's joining WTO, the domestic medical logistics is facing with a huge challenge. The medicine logistics enterprises are to make a new exploration and attempt to the logistics pattern, to establish and perfect their own supply chain mechanism, to build e-commerce platform, to develop the third-party logistics, etc.

\section{References}

[1] Zhan Xuefeng, Gong Shiwei. The thinking of the development of our medicine logistics management of our country. Medical Herald. 2012

[2]Wei Jigang. Policy Suggestions to promote the development of medical logistics in our country. China Business and Market. 2011

[3] Feng Zhidong. Modern medicine circulation problem research in our country. 2010

[4] Hou Yafei. The logistics distribution system construction research of the traditional medicine enterprise in EC environment. Science \& Technology Progress and Policy. 2012

[5] Bei Juan. The action pattern and logistics network research of third-party medical logistics enterprises. Chongqing: Management science and engineering college. 2012

[6] Clifford Flonch.Logistiesoutsoureing:AManagement Guide.Mcgraw,ine.New York:2011.

[7] Lin Huidan. The third-party logistics. Shanghai University of Finance and Economics Press. 2014

[8] Niu Zhengkun, Niu Zhengqian. The medicine logistics market development trend and path adjustment of our country. China Logistics \& Purchasing. 2004

[9] John Crowell. Editorial. Collaboration in Logistics [J]. European Journal of Operational Reseach.2013.

[10]Liu Xiaoliang, Wang Wenming. The problems and countermeasures of medical cold chain logistics development in China. Logistics engineering and management. 2010

[11] Zhang Ge. The current problems and improvement countermeasures of cold chain logistics in our country[J]. Sci-Tech Information Development \& Economy, 2011

[12] Alfred Burger ,Manfred E Burger, Medieinal Chestryand Drug Diseovery Haworth

Press,Ineorporated,2012 